\section{Prevalence of Dental Carious Lesions with Different Classes of Medications}

\section{Mabi Singh ${ }^{1 *}$, Athena S Papas ${ }^{1}$, Arthur N Papas ${ }^{2}$, Matt L Barker $^{3}$ and Aaron Biesbrock ${ }^{3}$}

${ }^{1}$ Division Oral Medicine, Department of Diagnostic Sciences, Tufts University School of Dental Medicine, 1 Kneeland St, Boston MA 02111, USA

${ }^{2}$ Department of Psychiatry, Massachusetts General Hospital, 55 Fruit Street, Boston, MA 02114, USA

${ }^{3}$ Procter\& Gamble Company, Global Oral Care, 8700 Mason-Montgomery Road Mason, $\mathrm{OH} 45040$, USA

\begin{abstract}
Background: Past research has produced conflicting results concerning the usage of medications and the associated oral health consequences. The authors examined non-cavitated and cavitated coronal and root carious lesions among subjects taking a variety of medications compared to those taking no medications to assess whether the effects of taking multiple medications had on carious lesion prevalence.

Objective: The objective of this study was to assess how the different classes of medication adversely affected the oral cavity, specifically in the formation of dental carious lesions.

Methods: A representative sample of 1028 volunteers aged 40-80 from the Greater Boston area, with at least 10 natural teeth were included in this study. After disqualifying subjects on medications with autoimmune conditions known to cause xerostomia, or a previous history of radiation to the head and neck area, 882 volunteers on medications known to cause salivary hypofunction and 146 volunteers taking no medications were enrolled. Non-cavitated and cavitated carious lesions were examined by a single calibrated dental examiner using visual and tactile methods. Major medication groups included psychiatric ( $\mathrm{N}=258)$, single antihypertensive $(\mathrm{N}=180)$, multiple antihypertensive including cardiac medications ( $\mathrm{N}=145)$, a combination of antihypertensive and psychiatric medications $(\mathrm{N}=85)$, anti-asthma medications ( $\mathrm{N}=67)$, Non-Steroidal Anti-Inflammatory (NSAIDs) $(\mathrm{N}=34)$ and all other medications $(\mathrm{N}=113)$.
\end{abstract}

*Corresponding author: Mabi Singh, Division Oral Medicine, Department of Diagnostic Sciences, Tufts University School of Dental Medicine, 1 Kneeland St, Boston MA 02111, USA, Tel: +1 6176363932; E-mail: mabi_I.singh@tufts.edu

Citation: Singh M, Papas AS, Papas AN, Barker ML, Biesbrock A (2015) Prevalence of Dental Carious Lesions with Different Classes of Medications. J Gerontol Geriatr Med1: 004.

Received: July 03, 2015; Accepted: August 21, 2015; Published: September 07,2015
Results: Subjects on psychiatric medications had the highest number of total carious lesions $(5.4 \pm 4.94)$ while those taking no medications had the least $(2.6 \pm 2.92)$. Subjects on a combination of antihypertensive and psychiatric medications had the highest number of carious root surface lesions $(1.18 \pm 4.06)$. Those subjects on anti-asthma medications exhibited the highest number of cavitated coronal surface lesions $(1.41 \pm 2.06)$.

Conclusion: This study found xerostomic medications vary in their deleterious effects on dental carious lesions. A combination of antihypertensive and psychiatric medications is the most detrimental, as evidenced by a higher prevalence of carious lesions in those participants taking them.

Clinical significance: As usage of concomitant xerogenic medications is likely to continue to increase, educating clinicians and the general public about the effects on oral health is essential to limiting dental carious lesions by instituting appropriate preventive protocols.

Keywords: Dental carious lesions; Medications; Side effects

\section{Introduction}

At age 55, the average American has a 35\% prevalence of root caries, making it the most common adult disease in the United States $[1,2]$. Dental caries is one of the primary causes of tooth loss among adults with $91 \%$ of the adult population affected by caries $[3,4]$. Numerous studies of dental caries in older adult populations have reported a high prevalence and incidence of both coronal and root caries. Those aged 75-85 years are particularly vulnerable to the disease, with the worldwide prevalence for the dentate elderly ranging from $35 \%-75 \%$, and a caries attack rate ranging from $0.31 / 100$ to $6.3 / 100$ surfaces/year [5]. In longitudinal studies, the caries experience of the elderly people over time exceeded that reported from cohort studies of adolescents, indicating that older adult caries is as serious a problem as childhood caries [6-8].

The elderly have multiple chronic diseases, multiple prescribers and use multiple medications [9]. It is important to assess the effect of medications on oral health. $90.1 \%$ of the $65+$ age group in the United States are taking at least one prescription medication [10]. Thomson et al., found that $95 \%$ of a $60+$ cohort were taking at least one medication at the study's 11-year follow-up [11]. With the baby boomer generation aging, the consequent rapid increase in the elderly population and the creation of new "designer" medications, it is expected that there will be a dramatic increase in the number of prescription and Over-the-Counter (OTC) medications taken.

Although salivary flow can vary between individuals, accepted mean whole saliva flow rates have been reported to be $0.3 \mathrm{ml} / \mathrm{min}$ for unstimulated saliva and $1.7 \mathrm{ml} / \mathrm{min}$ for stimulated saliva [12]. Thomson [13] suggested that 1 in 5 people had salivary hypofunction, based on salivary flow falling below $0.1 \mathrm{ml} / \mathrm{min}$. Navazesh et al., [14] and Bardow et al., [15] have suggested that $0.17 \mathrm{ml} / \mathrm{min}$ is the threshold below which oral pathologies, such as caries and periodontal disease occur, Among those who suffer with xerostomia, the oral health-related quality of life is affected significantly [16].

Neuronal control of salivation is extremely complex $[17,18]$. Pharmacological agents can mimic or antagonize numerous 
regulatory aspects of salivation, thus affecting both salivary flow rate and composition [19]. More than 450 commonly prescribed medications have been reported to induce salivary gland hypofunction and/or cause subjective oral dryness as a side effect [20]. Classes of xerogenic medications include anti-hypertensives, anti-cholinergics, antidepressants, antipsychotics, anxiolytics, mood stabilizers, antihistamines, proton-pump inhibitors and anti-asthma medications $[7,13,14,21-31]$.

Past research has produced conflicting results concerning a link between asthma medications and caries incidence. Meldrum et al., [32] found no significant differences in caries increment between asthma-free and asthma subjects. However, only $42.4 \%$ of the asthma subjects used anti-asthma medications, indicating that the medication rather than the condition may play a role. Consistent with this hypothesis, a longitudinal study by Ryberg et al., [33] reported that chronic treatment with beta2-adrenoceptor agonists in asthmatics caused a decrease in salivary flow and an increase in caries incidence. Thomson et al., [24] also found a statistically significant increase in coronal caries among anti-asthma medication users. Thomson [13] explained that it is difficult to determine how many of these symptoms are caused by the asthma medications taken and how many are caused by the increased effort in breathing and/or presence of chronic mouth breathing. Anti-asthma medications were included in this study to explore their effect on salivary flow and caries rate in a large aging population.

In a review article, Guggenheimer and Moore [34] reported the most frequent complications of xerostomia to be dental caries, candidiasis, and difficulty with the use of dentures. Nahriet al., [35] showed that individuals on medications had salivary flow rates significantly lower than those of healthy controls. It is commonly believed that dry mouth and declining salivary function are natural consequences of aging. However, recent research has indicated that salivary function is well preserved in older adults and any exhibited decrease in older individuals is not due to age but rather to the greater use of medications and an increase in chronic illnesses, both of which impact salivation [17,36,37]. In a 3 -year study of a $60+$ population, Persson et al., [38] found low salivary flow $(<0.01 \mathrm{ml} / \mathrm{min})$ in $31 \%$ of subjects taking medications known to cause xerostomia.

In both prevalence and incidence studies, adult caries have been associated with many factors including: low stimulated salivary flow, socioeconomic status, race, gender, age, type and frequency of professional care received, home care habits, smoking, alcohol consumption, fluoride use, systemic and periodontal conditions, and cariogenic microorganisms [25,30,39-56]. Caries is especially exaggerated in high-risk minority and uninsured populations with low incomes and poor access to dental care [8]. In this examination of medication classes and caries, the investigators attempted to control for some these factors by using a large sample size from community with fluoridated water and limited the age range to 40-80 year old.

\section{Methods}

This report is based on a cross-sectional database of subjects who were recruited throughout the Greater Boston area. In an effort to establish a representative sample of a free-living, ambulatory, and a demographically diverse cross section of middle aged and elderly adults. Subjects were recruited at places of employment, nutritional sites, health fairs, from geriatric housing complexes, via ads in local and city newspapers, and through staff members of the Boston Council on Aging. Additionally, 5,000 letters were sent out by the
USDA Human Nutrition Research Center on Aging located at Tufts University. All advertisements and letters were approved by the Tufts Institutional Review Board (IRB).

All subjects included in this analysis were from varying socioeconomic backgrounds, aged 40-80 years old, with a group on at least one medication and a control group not on any medication all had at least 10 natural teeth. Subjects were excluded who had autoimmune conditions known to cause xerostomia, or a previous history of radiation to the head and neck area. IRB-approved informed consent forms were explained to and signed by all subjects.

A detailed medical history, including a list of current medications (both prescription and OTC), the reason for taking each medication, and the frequency and duration of medication use, was collected from each subject and verified by the research staff. Subjects were asked to bring their medications physically to the study site [57]. Those who forgot them were called at home and asked to read the medication labels to the study staff for verification. An attitudinal questionnaire on oral health behavior and practice was also obtained. Usage of a non-prescription fluoride dentifrice as part of their daily home oral hygiene regimen was confirmed. It should be noted that the Boston area was not a fluoridated community until 1978.

Saliva was collected from each subject in the morning after they had refrained from brushing and eating for at least 1.5 hours prior to the visit. Both whole unstimulated salivary flow rate using the drooling method (Dawes technique) [58] and whole stimulated salivary flow rate with sterile paraffin wax were measured. The paraffin wax was standardized for weight and size, supplied in blister packs. A clinical oral examination was conducted using artificial light, an explorer, a mirror, and an air syringe. A single dental examiner was calibrated against a gold standard (Dr. Pramod Soparkar) and the criteria used were the based on Pitts Diagnostic Criteria. These criteria determined no lesions, clinically detectable enamel lesions on intact surfaces (incipient lesions), clinically detectable "cavities" limited to enamel or dentin (frank or established lesions) on the tooth surface [59] and the detection of caries on the root surfaces according to Banting [60].

Medications were categorized according to indications cited by the subjects. From the vast range of medications reported those most frequently used were anti-hypertensive, psychiatric, anti-asthma, and analgesics. Other groups included in the analysis were thyroid medications, Hormone Replacement Therapy (HRT), and cholesterol lowering medications. All reported groups included a minimum sample size of 23 subjects. The number of non-cavitated and cavitated coronal and root carious lesions was included in the statistical analysis.

The primary outcome measures were the number of root, crown, cavitated, and non-cavitated carious lesions. This data was normalized by the number of surfaces at risk for each subject. Because these variables were skewed, non-parametric procedures were used for univariable testing and the natural logs of the variables were used for multiple linear regression analyses. Forward stepwise regression was used with standard least squares techniques, with a 0.05 level of significance to enter variables and 0.10 to remove them, the stepwise procedure ending when no more independent variables could be entered into the predictive equation. The coefficients of the fitted model were examined for the form of the relationships and the total $\mathrm{R}^{2}$ (coefficient of determination) was used to summarize the quality of fit of the whole model. Statistics at each step were examined for 
evidence of confounding, and the order of entry and change in $\mathrm{R}^{2}$ interpreted as the cumulative effect of each explanatory variable. Similarly, the number of caries total and of each type, were considered as dichotomous variables ("any" versus "none") and stepwise multiple logistic regression with the maximum likelihood method used to estimate the coefficients and likelihood ratio tests used for entry and removal of variables. Exponentiation of the coefficients estimated the odds ratio of outcome for each independent variable, and Nagelkerke $\mathrm{R}^{2}$ was used for model assessment. Data were entered into Statistical Product and Service Solutions Software (SPSS) for the analyses.

\section{Results}

Of the 1028 subjects screened from the inner city and Greater Boston area, 882 patients were on at least once medication and 146 were not on any medication. $55 \%$ percent of the medicated population earned below $\$ 35,000$ per year, with $22.7 \%$ choosing not to disclose their income.

Oral health behaviors, including brushing, flossing, and frequency of dental visits, were greater for the medicated group as compared to the non-medicated group (Table 1).

\begin{tabular}{|c|c|c|c|}
\hline & Medications & No Medications & $\mathbf{p}$ \\
\hline Root Caries & $1.43+/-2.38$ & $.57+/-1.21$ & 0.0001 \\
\hline Coronal Caries & $3.02+/-2.87$ & $2.09+/-2.32$ & 0.0001 \\
\hline Dental Visits/yr. & $1.9+/-.98$ & $1.2+/-.66$ & 0.0001 \\
\hline Flossing & $1-3 / \mathrm{wk}$ & Rarely & 0.001 \\
\hline Brushing & 2/day & 2/day & NS \\
\hline
\end{tabular}

Table 1: Comparison of medicated and non-medicated groups.

A stepwise linear regression was used to predict the relationship of independent variables with the outcome of total carious lesions on the crown. T-tests were done and all variables with a significance of 0.1 were entered into the model (Table 2). Results indicate that psychiatric medications were significant $(p \leq 0.004)$ for increased number of carious lesions when other independent variables were used with the model. The number of surfaces at risk present, type of dental care received, smoking, age and gender of the subjects were associated with total coronal carious lesions, while frequent dental visits and flossing was negatively associated with caries development.

\begin{tabular}{|c|c|c|c|}
\hline Variable & Beta & T & Significance \\
\hline Psychiatric medication & 0.14 & 4.193 & 0.0001 \\
\hline Flossing & -0.135 & -4.021 & 0.0001 \\
\hline Smoking & -0.17 & 5.093 & 0.0001 \\
\hline Male gender & 0.094 & 2.81 & 0.005 \\
\hline Age & -0.161 & -4.806 & 0.0001 \\
\hline Type of dental care & -0.181 & -5.445 & 0.0001 \\
\hline African American & 0.071 & 2.118 & 0.034 \\
\hline
\end{tabular}

Table 2: Evaluation of exterior factors on the likelihood of developing coronal caries for medicated subjects.

Root caries: Subjects on a combination of antihypertensive and psychiatric medications had the highest number of cavitated root surfaces $(1.18 \pm 4.06)$ followed by those on only psychiatric medications $(0.84 \pm 2.65)$. Subjects on anti-asthma medications, the majority of which were bronchodilators, had $0.77 \pm 1.90$ carious root lesions. Subjects taking no medications had $0.27 \pm 0.69$ cavitated root surfaces.
Coronal caries: The users of anti-asthma medications exhibited the highest cavitated coronal surface lesions $(1.41 \pm 2.06)$. The psychiatric group had $1.09 \pm 1.92$ carious coronal lesions followed by proton pump inhibitors $(1.07 \pm 2.40)$. The combination of antihypertensive and psychiatric medications had $0.95 \pm 1.62$ carious surface lesions. Subjects on NSAIDs had the least number of cavitated surfaces $(0.382 \pm 0.94)$. Those taking no medications had $0.83 \pm 1.49$ cavitated coronal surface lesions.

Interproximal caries: Existing and new interproximal carious lesions were probably highly underestimated because the study parameters did not allow for radiographic studies.

Recurrent caries: Carious lesions around existing restorations were counted as carious lesions.

Total caries: The mean number of total carious lesions (non-cavitated and cavitated on both coronal and root surfaces) for the medication group was found to be $4.41 \pm 3.95$. The subjects on psychiatric mediations had the highest number of total carious lesions $(5.4 \pm 4.94)$, while those on blood pressure medication had (3.8 \pm 2.77$)$. When the psychiatric group was compared to the NSAID group $(2.81 \pm 2.40)$ or the Hormone Replacement Therapy (HRT) (3.14 \pm 2.35$)$, total caries was significantly less in both groups - the NSAID group ( $\mathrm{p} \leq 0.0001)$ and the HRT group $(\mathrm{p} \leq 0.006)$. Those taking no medications had a total of $2.64 \pm 2.92$ carious lesions significantly lower than the medication group (Table 3 ).

Number of medications: There was no difference in the number of medications taken by males and females. The average number of medications ranged from 1 to 15 with a mean of $3.5 \pm 2.4$. Those on a combination of blood pressure and psychiatric medications were taking the highest number of medications $(6.11 \pm 2.99)$ (Table 4$)$. The stimulated salivary flow rate was significantly higher for subjects on one medication than for those on 5 or more medications $(\mathrm{p} \leq 0.0001)$.

Saliva: The average whole unstimulated salivary flow and whole paraffin stimulated salivary flow for this population was $0.06 \pm 0.85$ $\mathrm{ml} / \mathrm{min}$ and $1.53 \pm 1.07 \mathrm{ml} / \mathrm{min}$, respectively. Male subjects $(1.81 \pm 1.22$ $\mathrm{ml} / \mathrm{min}$ ) showed a significantly higher stimulated salivary output than females $(1.32 \pm 0.89 \mathrm{ml} / \mathrm{min})(\mathrm{p} \leq 0.0001)$ while unstimulated flow was nearly equivalent at $0.06 \pm 0.08 \mathrm{ml} / \mathrm{min}$ for both genders. The subjects on psychiatric medications had significantly lower stimulated saliva $(1.33 \pm 0.99 \mathrm{ml} / \mathrm{min}, \mathrm{p} \leq 0.001)$ with unstimulated salivary flow $(0.04 \pm 0.07 \mathrm{ml} / \mathrm{min} \mathrm{p} \leq 0.019)$. This difference in salivary flow corresponds to higher caries prevalence both in root and coronal caries in the psychiatric group. Salivary flow in the non-medicated participants was significantly higher US $(0.14 \pm .28) \mathrm{p} \leq 0.0001$ and SS $(1.72 \pm 1.22) \mathrm{p} \leq 0.011$ than those taking psychiatric medications.

Smoking: Very few subjects were current smokers with the majority of smokers being in the psychiatric medication group (14\% current smokers and $31 \%$ past smokers). The psychiatric group exhibited good oral health behavior and a high frequency of dental visits, which eliminated poor oral health behavior as a major factor for caries in this group. Subjects in this group exhibited significantly lower stimulated salivary flow $(0.49 \pm 0.075 \mathrm{ml} / \mathrm{min})$, which may be responsible for the higher caries prevalence seen. When the psychiatric group of smokers was compared to the non-smokers, the smokers had significantly more coronal and root caries than those who did not smoke. Despite this, the non-smokers of the psychiatric group still had significantly higher caries prevalence than subjects in any of the other medicated groups $(\mathrm{p} \leq 0.009)$, indicating that psychiatric 
Citation: Singh M, Papas AS, Papas AN, Barker ML, Biesbrock A (2015) Prevalence of Dental Carious Lesions with Different Classes of Medications. J Gerontol Geriatr Med1: 004.

- Page 4 of 7 •

\begin{tabular}{|c|c|c|c|c|c|c|c|c|c|}
\hline Medication group & $\mathbf{N}$ & $\begin{array}{c}\text { Average } \\
\text { Number of }\end{array}$ & Number crown & Number root & $\begin{array}{c}\text { Average } \\
\text { Number of }\end{array}$ & \multicolumn{2}{|c|}{ Coronal caries $\pm \mathrm{SD}$} & \multicolumn{2}{|c|}{ Root caries \pm SD } \\
\hline & & & & & & Non-cavitated & Cavitated & Non-cavitated & Cavitated \\
\hline No Medication & $146(9.7 \%)$ & 0 & 106.45 & 94 & 24.9 & $1.25 \pm 1.54$ & $0.83 \pm 1.49$ & $.31 \pm .87$ & $.27 \pm .69$ \\
\hline \multirow[t]{2}{*}{ Psychiatric } & $258(25.09 \%)$ & 4.4 & 107.65 & 94.85 & 23.8 & $2.42 \pm 1.94$ & & $0.93 \pm 1.51$ & $0.84 \pm 2.65$ \\
\hline & & & & & & & $1.09 \pm 1.92$ & & \\
\hline \multirow[t]{2}{*}{ Antihypertensive alone } & $180(12.41 \%)$ & 2.6 & 103.26 & 91.37 & 22.8 & $2.00 \pm 1.94$ & & $0.69 \pm 1.03$ & $0.48 \pm 0.97$ \\
\hline & & & & & & & $0.65 \pm 1.05$ & & \\
\hline $\begin{array}{l}\text { Multiple antihypertensive } \\
\text { including }\end{array}$ & $145(14.10 \%)$ & 4.5 & 102.86 & 91.06 & 22.8 & $1.91 \pm 2.19$ & $0.70 \pm 1.43$ & $1.04 \pm 1.39$ & $0.57 \pm 1.7$ \\
\hline \multicolumn{10}{|l|}{ cardiovascular } \\
\hline $\begin{array}{l}\text { Antihypertensive and } \\
\text { psychiatric }\end{array}$ & $85(8.2 \%)$ & 6.1 & 102.75 & 91.23 & 22.9 & $2.17 \pm 1.87$ & $0.95 \pm 1.62$ & $0.87 \pm 1.60$ & $1.18 \pm 4.06$ \\
\hline Anti-asthma & $67(6.5 \%)$ & 5.5 & 105.73 & 92.93 & 23.4 & $2.55 \pm 2.05$ & $1.41 \pm 2.06$ & $0.68 \pm 1.33$ & $0.77 \pm 1.9$ \\
\hline NSAIDs & $34(3.3 \%)$ & 2.6 & 109.75 & 96.26 & 22.7 & $1.59 \pm 1.39$ & $0.382 \pm 0.94$ & $0.55 \pm 0.88$ & $0.23 \pm 0.62$ \\
\hline Cholesterollowering & $33(3.2 \%)$ & 1.6 & 101.06 & 88.75 & 22.4 & $1.94 \pm 1.88$ & $0.61 \pm 0.97$ & $0.55 \pm .0794$ & $0.55 \pm 0.94$ \\
\hline HRT & $29(2.8 \%)$ & 1.9 & 109.5 & 96.15 & 24 & $1.62 \pm 1.08$ & $0.52 \pm 0.986$ & $0.66 \pm 0.974$ & $0.34 \pm 0.86$ \\
\hline Proton pump inhibitors & $28(2.7 \%)$ & 2.1 & 110 & 96 & 24.3 & $2.43 \pm 1.77$ & $1.07 \pm 2.4$ & $0.82 \pm 1.52$ & $0.46 \pm 1.07$ \\
\hline $\begin{array}{c}\text { Thyroid replacement } \\
\text { therapy }\end{array}$ & $23(2.2 \%)$ & 2.1 & 102.17 & 90.96 & 22.7 & $1.96 \pm 1.18$ & $0.65 \pm 1.402$ & $0.91 \pm 1.28$ & $1.04 \pm 1.46$ \\
\hline
\end{tabular}

Table 3: Principle medication groups including number of subjects, mean age, coronal/ 100 surfaces, and root/ 100 surfaces caries status for groups with more than 23 subjects.

\begin{tabular}{|c|c|c|c|c|c|c|}
\hline & \multirow{3}{*}{ Percent of the total patients } & \multirow{3}{*}{ Number of teeth } & \multirow{2}{*}{\multicolumn{2}{|c|}{$\begin{array}{c}\text { Coronal lesions } \\
( \pm \mathrm{SD})\end{array}$}} & \multirow{2}{*}{\multicolumn{2}{|c|}{$\begin{array}{c}\text { Root lesions } \\
( \pm \mathrm{SD})\end{array}$}} \\
\hline & & & & & & \\
\hline & & & Non-cavitated & Cavitated & Non-cavitated & Cavitated \\
\hline \multicolumn{7}{|c|}{ Number of medications } \\
\hline 1 & $22 \%$ & 23.3 & $1.98 \pm 1.8$ & $0.73 \pm 1.34$ & $0.69 \pm 1.02$ & $0.44 \pm 0.89$ \\
\hline 2 & $21 \%$ & 23.5 & $2.02 \pm 1.8$ & $0.80 \pm 1.44$ & $0.73 \pm 1.08$ & $0.55 \pm 1.19$ \\
\hline 3 & $16 \%$ & 22.7 & $2.28 \pm 2.18$ & $0.95 \pm 1.8$ & $0.96 \pm 1.29$ & $0.96 \pm 3.3$ \\
\hline 4 & $14 \%$ & 127 & $1.97 \pm 1.69$ & $0.91 \pm 1.66$ & $0.74 \pm 1.32$ & $0.68 \pm 1.68$ \\
\hline 5 or more & $27 \%$ & 23.0 & $2.27 \pm 2.23$ & $0.97 \pm 1.77$ & $0.88 \pm 1.43$ & $0.61 \pm 1.26$ \\
\hline \multicolumn{7}{|l|}{ Race } \\
\hline Asian & $2 \%$ & 24.7 & $1.9 \pm 2.1$ & $0.81 \pm 1.53$ & $0.7 \pm 0.95$ & $0.57 \pm 1.12$ \\
\hline African Amer. & $8 \%$ & 21.8 & $2.78 \pm 2.5$ & $1.68 \pm 2.30$ & $0.73 \pm 1.04$ & $0.71 \pm 1.32$ \\
\hline Caucasian & $87 \%$ & 23.2 & $2.07 \pm 1.92$ & $0.79 \pm 1.49$ & $0.83 \pm 1.29$ & $0.63 \pm 1.78$ \\
\hline Hispanic & $1 \%$ & 21.5 & $2.25 \pm 1.68$ & $1.33 \pm 2.14$ & $0.33 \pm 0.65$ & $0.42 \pm 0.66$ \\
\hline Native Amer. & $1 \%$ & 24.6 & $1.60 \pm 1.5$ & $0.20 \pm .044$ & $0.40 \pm 0.89$ & $0 \pm 0$ \\
\hline Unknown & $1 \%$ & 21.7 & $3.7 \pm 2.2$ & $1.30 \pm 2.05$ & $0.50 \pm 0.7$ & $0.50 \pm 0.85$ \\
\hline \multicolumn{7}{|l|}{ Income } \\
\hline$<15,000$ & $24 \%$ & 22.1 & $2.22 \pm 1.8$ & $0.97 \pm 1.93$ & $0.93 \pm 1.32$ & $0.97 \pm 1.9$ \\
\hline $15,000-34,999$ & $27 \%$ & 22.6 & $2.09 \pm 2.1$ & $0.67 \pm 2.37$ & $0.75 \pm 1.22$ & $0.67 \pm 2.3$ \\
\hline $35,000-54,999$ & $16 \%$ & 23.6 & $2.04 \pm 2.26$ & $0.46 \pm 0.98$ & $0.70 \pm 1.25$ & $0.46 \pm 0.98$ \\
\hline $55,000-74,999$ & $6 \%$ & 25.4 & $2.31 \pm 1.95$ & $0.23 \pm 0.64$ & $0.52 \pm 1.02$ & $0.23 \pm 0.64$ \\
\hline $75,000-84,999$ & $3 \%$ & 24.3 & $1.85 \pm 1.08$ & $0.19 \pm 0.40$ & $0.69 \pm 1.05$ & $0.19 \pm .40$ \\
\hline$>95,000$ & $3 \%$ & $25.2^{*}$ & $2.27 \pm 1.80$ & $0.31 \pm 0.62$ & $1.04 \pm 1.50$ & $0.35 \pm 1.01$ \\
\hline Did not disclose & $21 \%$ & 23.5 & $2.15 \pm 1.94$ & $0.74 \pm 1.30$ & $0.87 \pm 1.24$ & $0.52 \pm 1.07$ \\
\hline
\end{tabular}


Citation: Singh M, Papas AS, Papas AN, Barker ML, Biesbrock A (2015) Prevalence of Dental Carious Lesions with Different Classes of Medications. J Gerontol Geriatr Med1: 004 .

- Page 5 of 7 •

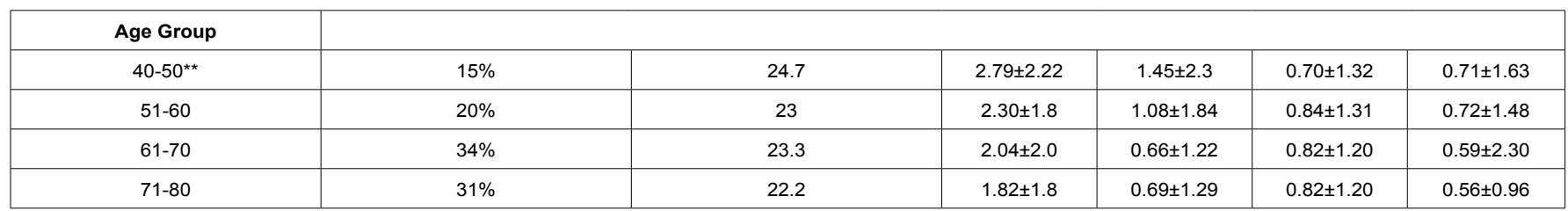

Table 4: Non-cavitated and cavitated lesions in relation to medication number, race, income, and age.

*The higher-income subjects had significantly more teeth.

**The younger group had significantly more teeth, more coronal caries/100 surfaces, and less root caries/100 surfaces ( $p>0.0001$ ).

medications serve as a major caries risk factor. In the non-medicated subjects, $16.2 \%$ were smokers.

In a model with total carious lesions, it was found that the African Americans, significance was found on who were on antihypertensive medications $(p=0.032)$ and the lower frequency of dental care $(\mathrm{p}=0.004)$.

\section{Discussion}

This study examined non-cavitated and cavitated coronal and root carious lesions among subjects taking various classes of medications and those taking no medications. The main groups of medications assessed were antihypertensive, psychiatric (including mostly antidepressants, anti-anxiety, and sleep medications), a combination of psychiatric and antihypertensive, NSAIDs, and anti-asthma medications. Results suggest that subjects on psychiatric medications, and especially those on a combination of antihypertensive and psychiatric medications, exhibited the highest caries prevalence, both in cavitated and total carious surfaces. Cavitated carious lesions in the coronal portion were seen most frequently in subjects using anti-asthma medications as compared to those not using anti-asthma medications, which is a finding similar to that of Thomson et al., [24]. This higher caries prevalence may be due to the acidic nature of the medication itself ( $\mathrm{pH}$ 5.5) as suggested by Kargul et al., [61] but deserves further exploration. The $\mathrm{pH}$ at which enamel demineralization occurs is 5.5 .

The psychiatric group exhibited the second highest prevalence of cavitated coronal carious lesions, which is consistent with Rindal et al., [62] examination of the association between xerogenic antidepressant medication use and dental restorations. The current study also found significantly lower stimulated salivary flow, which corresponded to higher caries prevalence both in root and coronal carious lesions in the psychiatric group. This result is supported by Bergdahl and Bergdahl [27], who found unstimulated salivary flow and subjective oral dryness to be significantly associated with intake of antidepressants. It is important to note that they suggested that xerostomia in subjects taking psychiatric medications may not be due solely to the medications. It also may be due to the depression, stress, and anxiety reported by this population. Meta-analysis done by Alavaikko et al., concluded that the risk of dental caries was approximately doubled in relation to asthma, possibly due to medications' effects on saliva secretion and the content of secretory immunoglobulin A's contributing to both asthma and caries [63].

When non-cavitated and cavitated coronal and root carious lesions were analyzed, subjects on multiple psychiatric medications had the highest number of total carious lesions, followed by those using anti-asthma medications. Similar to Thomson et al., finding, proton pump inhibitors also demonstrated a high level of total carious lesions, which is consistent with data reported for both Australian and Swedish populations $[23,64]$. A contributor to the caries prevalence in

this group may be related to gastroesophageal reflux, which is known to cause demineralization of the teeth and should be further assessed.

Peker et al., [65] compared a medicated to a non-medicated group that exhibited statistically significant differences $(p<0.05)$ between the groups for dental caries, amalgam, fixed and removable prosthetic restorations and missing teeth. This study confirmed the results of a previous study by the same investigators conducting this study [31]. Conversely, Janket et al., [65] found no significant increase in coronal caries prevalence among 345 male veterans taking xerostomic medications versus those taking non-xerostomic medications. However, Janket and colleagues did not confirm the presence of saliva hypofunction in either the xerostomic or non-xerostomic medications groups in this veteran's administration's outpatient population.

African Americans had the highest caries rate reflecting their poorer access to care, usage of anti-hypertensive medication. The male and female subjects in the current study were on a comparable number of medications, yet the males demonstrated a higher prevalence of total caries despite a lower level of hyposalivation than the women. As suggested by Janket et al., [66] this result indicates that the detrimental effects of xerostomic medications may be reduced as long as patients are capable of practicing good oral hygiene. Based upon the analysis from this study, multiple factors, including gender, dental visit frequency, oral homecare, income, psychiatric medications, stimulated saliva, and smoking, should be considered when assessing a medicated population.

The current study was limited in the lack of sub classification when grouping medication types. Further analysis of medication groups with classification by mechanism of action is necessary to gain more insight into the causal relationship between medication type and carious lesion formation. Additionally, a cross-sectional study is limited by the nature of its design, and further research examining the longitudinal effects of classes of medications on oral health is certainly warranted.

\section{Conclusion}

Various classes of medications with dry mouth listed as a side effect in the physician's desk reference were grouped to see if that translated into more dental carious lesions. Even with the frequency of dental visits and good oral health behaviors (flossing was a surrogate for this) correlating to statistically significantly higher protective results, this study demonstrated that subjects on medications had more carious lesions than subjects not on medications.

Based upon the medication classifications results from this study indicated that xerogenic medication vary in their deleterious effects on oral health as evidenced by differing caries prevalence rates. As polypharmacy continues to grow, educating clinicians and the general public concerning the oral effects of xerostomic medication is essential to limiting the prevalence and impact of caries. The dental treatment should include the multiple modalities based on the risk of 
Citation: Singh M, Papas AS, Papas AN, Barker ML, Biesbrock A (2015) Prevalence of Dental Carious Lesions with Different Classes of Medications. J Gerontol Geriatr Med1: 004 .

developing carious lesions. They would include oral hygiene instruction, prescription strength fluoride treatment, remineralizing agents, saliva stimulation with xylitol gum, restriction of dietary fermentable carbohydrates and regular dental care.

Larger studies with individual medication class and quantifying serum anti-cholinergic activity and assessment of the dental carious lesions are needed to establish a causal relationship.

\section{References}

1. Winn DM, Brunelle JA, Selwitz RH, Kaste LM, Oldakowski RJ, et al. (1996) Coronal and root caries in the dentition of adults in the United States, 1988 1991. J Dent Res 75: 642-651.

2. Lethbridge-Cejku M, Schiller JS, Bernadel L (2004) Summary health statistics for US adults: National Health Interview Survey, 2002. Vital Health Stat 10: $1-151$.

3. Chauncey HH, Glass RL, Alman JE (1989) Dental caries. Principal cause of tooth extraction in a sample of US male adults. Caries Res 23: 200-205.

4. Beltrán-Aguilar ED, Barker LK, Canto MT, Dye BA, Gooch BF, et al. (2005) Surveillance for dental caries, dental sealants, tooth retention, edentulism, and enamel fluorosis--United States, 1988-1994 and 1999-2002. MMWR Surveill Summ 54: 1-43.

5. Griffin SO, Griffin PM, Swann JL, Zlobin N (2005) New coronal caries in olde adults: implications for prevention. J Dent Res 84: 715-720.

6. Griffin SO, Griffin PM, Swann JL, Zlobin N (2004) Estimating rates of new root caries in older adults. J Dent Res 83: 634-638.

7. Thomson WM (2004) Dental caries experience in older people over time: what can the large cohort studies tell us? Br Dent J 196: 89-92.

8. Joshi A, Papas AS, Giunta J (1993) Root caries incidence and associated risk factors in middle-aged and older adults. Gerodontology 10: 83-89.

9. Roth MT, Weinberger M, Campbell WH (2009) Measuring the quality of medication use in older adults. J Am Geriatr Soc 57: 1096-1102.

10. CDC (2009) National Center for Health Statistics/Office of Analysis and Epidemiology.

11. Murray Thomson W, Chalmers JM, John Spencer A, Slade GD, Carter KD (2006) A longitudinal study of medication exposure and xerostomia among older people. Gerodontology 23: 205-213.

12. Dawes C (1996) Factors influencing salivary flow rate and composition. In Edgar WM, O'Mullane DM (eds.). Saliva and Oral Health, (2nded). Br Dent Association British Dental Journal, London, UK.

13. Thomson WM (2005) Issues in the epidemiological investigation of dry mouth Gerodontology 22: 65-76.

14. Navazesh M, Brightman VJ, Pogoda JM (1996) Relationship of medical status, medications, and salivary flow rates in adults of different ages. Oral Surg Oral Med Oral Pathol Oral Radiol Endod 81: 172-176.

15. Bardow A, Nyvad B, Nauntofte B (2001) Relationships between medication intake, complaints of dry mouth, salivary flow rate and composition, and the rate of tooth demineralization in situ. Arch Oral Biol 46: 413-423.

16. Ciancio SG (2004) Medications' impact on oral health. J Am Dent Assoc 135 1440-1448.

17. Locker D (2003) Dental status, xerostomia and the oral health-related quality of life of an elderly institutionalized population. Spec Care Dentist 23: 86-93.

18. Baum BJ (1987) Saliva secretion and composition. Front Oral Physiol 6: $126-$ 134

19. Baum BJ, Dai Y, Hiramatsu Y, Horn VJ, Ambudkar IS (1993) Signaling mechanisms that regulate saliva formation. Crit Rev Oral Biol Med 4: 379-384

20. Schubert MM, Izutsu KT (1987) latrogenic causes of salivary gland dysfunction. J Dent Res 66: 680-688.
21. Sreebny LM (2004) A useful source for the drug-dry mouth relationship. J Dent Educ 68: 6-7.

22. Grad H, Grushka M, Yanover L (1985) Drug induced xerostomia. The effects and treatment. J Can Dent Assoc 51: 296-300.

23. Thomson WM, Slade GD, Spencer AJ (1995) Dental caries experience and use of prescription medications among people aged 60+ in South Australia. Gerodontology 12: 104-110.

24. Thomson WM, Chalmers JM, Spencer AJ, Slade GD (2000) Medication and dry mouth: findings from a cohort study of older people. J Public Health Dent 60: $12-20$.

25. Thomson WM, Spencer AJ, Slade GD, Chalmers JM (2002) Is medication a risk factor for dental caries among older people? Community Dent Oral Epidemiol 30: 224-232

26. Sreebny LM, Schwartz SS (1997) A reference guide to drugs and dry mouth2nd edition. Gerodontology 14: 33-47.

27. Bergdahl M, Bergdahl J (2000) Low unstimulated salivary flow and subjective oral dryness: association with medication, anxiety, depression, and stress. J Dent Res 79: 1652-1658.

28. Sjögren R, Nordström G (2000) Oral health status of psychiatric patients. Clin Nurs 9: 632-638.

29. Bowden GH (1990) Microbiology of root surface caries in humans. J Dent Res 69: 1205-1210.

30. Papas AS, Joshi A, MacDonald SL, Maravelis-Splagounias L, Pretara-Spanedda $P$, et al. (1993) Caries prevalence in xerostomic individuals. J Can Dent Assoc 59: 171-174, 177-179

31. Calvo J, Papas A (2003) Caries prevalence, nutrition, and xerogenic medication use among a geriatric population. J Mass Dent Soc 52: 48-51.

32. Meldrum AM, Thomson WM, Drummond BK, Sears MR (2001) Is asthma a risk factor for dental caries? Finding from a cohort study. Caries Res 35 235-239.

33. Ryberg M, Möller C, Ericson T (1991) Saliva composition and caries development in asthmatic patients treated with beta 2-adrenoceptor agonists: a 4-year follow-up study. Scand J Dent Res 99: 212-218.

34. Guggenheimer J, Moore PA (2003) Xerostomia: etiology, recognition and treatment. J Am Dent Assoc 134: 61-69.

35. Närhi TO, Vehkalahti MM, Siukosaari P, Ainamo A (1998) Salivary findings daily medication and root caries in the old elderly. Caries Res 32: 5-9.

36. Ship JA, Pillemer SR, Baum BJ (2002) Xerostomia and the geriatric patient. J Am Geriatr Soc 50: 535-543.

37. Vissink A, Spijkervet FK, Van Nieuw Amerongen A (1996) Aging and saliva: a review of the literature. Spec Care Dentist 16: 95-103.

38. Persson RE, Persson GR, Kiyak HA, Powell LV (1998) Oral health and medical status in dentate low-income older persons. Spec Care Dentist 18: 70-77.

39. Sumney DL, Jordan HV, Englander HR (1973) The prevalence of root surface caries in selected populations. J Periodontol 44: 500-504

40. Ravald N, Hamp SE (1981) Prediction of root surface caries in patients treated for advanced periodontal disease. J Clin Periodontol 8: 400-414.

41. Osterberg $T$, Hedegård $B$, Säter $G$ (1984) Variation in dental health in 70-year old men and women in Göteborg, Sweden. A cross-sectional epidemiological study including longitudinal and cohort effects. Swed Dent J 8: 29-48.

42. Burt BA, Ismail AI, Eklund SA (1986) Root caries in an optimally fluoridated and a high-fluoride community. J Dent Res 65: 1154-1158.

43. Vehkalahti MM, Paunio IK (1988) Occurrence of root caries in relation to dental health behavior. J Dent Res 67: 911-914.

44. Drake CW, Beck JD (1992) Models for coronal caries and root fragments in an elderly population. Caries Res 26: 402-407. 
Citation: Singh M, Papas AS, Papas AN, Barker ML, Biesbrock A (2015) Prevalence of Dental Carious Lesions with Different Classes of Medications. J Gerontol Geriatr Med1: 004.

45. Faine MP, Allender D, Baab D, Persson R, Lamont RJ (1992) Dietary and salivary factors associated with root caries. Spec Care Dentist 12: 177-182.

46. Powell LV, Leroux BG, Persson RE, Kiyak HA (1998) Factors associated with caries incidence in an elderly population. Community Dent Oral Epidemiol 26: $170-176$.

47. Graves RC, Beck JD, Disney JA, Drake CW (1992) Root caries prevalence in black and white North Carolina adults over age 65. J Public Health Dent 52: $94-101$.

48. Papas AS, Joshi A, Belanger AJ, Kent RL Jr, Palmer CA, et al. (1995) Dietary models for root caries. Am J Clin Nutr 61: 417-422.

49. Drake CW, Beck JD, Lawrence HP, Koch GG (1997) Three-year coronal caries incidence and risk factors in North Carolina elderly. Caries Res 31: 1-7.

50. Papas AS, Joshi A, Palmer CA, Giunta JL, Dwyer JT (1995) Relationship of diet to root caries. Am J Clin Nutr 61: 423-429.

51. Sakki TK, Knuuttila ML, Vimpari SS, Kivelä SL (1994) Lifestyle, dental caries and number of teeth. Community Dent Oral Epidemiol 22: 298-302.

52. Drake CW, Hunt RJ, Koch GG (1995) Three-year tooth loss among black and white older adults in North Carolina. J Dent Res 74: 675-680.

53. Singh M, Papas A, Vollmer W, Bader J, Laws R, et al. (2013) Predictors of coronal caries progression in adults: results from the Prevention of Adult Caries Study. Community Dent Oral Epidemiol 41: 558-564.

54. Locker D (1996) Incidence of root caries in an older Canadian population Community Dent Oral Epidemiol 24: 403-407.

55. Beck JD, Kohout F, Hunt RJ (1988) Identification of high caries risk adults: attitudes, social factors and diseases. Int Dent J 38: 231-238.
56. Gilbert GH, Foerster U, Dolan TA, Duncan RP, Ringelberg ML (2000) Twenty-four month coronal caries incidence: the role of dental care and race. Caries Res 34: 367-379.

57. Kendrick R, Bayne JR (1982) Compliance with prescribed medication by elderly patients. Can Med Assoc J 127: 961-962.

58. Dawes C (1987) Physiological factors affecting salivary flow rate, oral sugar clearance, and the sensation of dry mouth in man. J Dent Res 66: 648-653.

59. Ismail Al (2004) Visual and visuo-tactile detection of dental caries. J Dent Res 83: 56-66.

60. Banting DW, Papas A, Clark DC, Proskin HM, Schultz M, et al. (2000) The effectiveness of $10 \%$ chlorhexidine varnish treatment on dental caries incidence in adults with dry mouth. Gerodontology 17: 67-76.

61. Kargul B, Tanboga I, Ergeneli S, Karakoc F, Dagli E (1998) Inhaler medicament effects on saliva and plaque $\mathrm{pH}$ in asthmatic children. $\mathrm{J}$ Clin Pediatr Dent 22: 137-140.

62. Rindal DB, Rush WA, Peters D, Maupomé G (2005) Antidepressant xerogenic medications and restoration rates. Community Dent Oral Epidemiol 33: 74-80

63. Alavaikko S, Jaakkola MS, Tjäderhane L, Jaakkola JJ (2011) Asthma and Caries: A Systematic Review and Meta-Analysis. Am J Epidemiol 174: 631 641.

64. Fure S (1998) Five-year incidence of caries, salivary and microbial conditions in 60-, 70- and 80-year-old Swedish individuals. Caries Res 32: 166-174.

65. Peker I, Alkurt MT, Usalan G (2008) Clinical evaluation of medications on oral and dental health. Int Dent J 58: 218-222.

66. Janket SJ, Jones JA, Rich S, Meurman J, Garcia R, et al. (2003) Xerostomic medications and oral health: the Veterans Dental Study (part I). Gerodontology 20: 41-49. 